\title{
Effect of Social Media Usage on Research Competences and Completion during COVID-19: Case of Pre-Service Health Sciences Researchers
}

Muhammad Zaheer Asghar ( $\square$ zaheer.asghar@helsinki.fi )

University of Helsinki

\section{Seema Arif}

University of Management and Technology, Lahore

Pirita Seitamaa Hakkarainen

University of Helsinki

Junaid Sarfraz Khan

National University of Medical Sciences, Rawalpindi

\section{Research Article}

Keywords: Social Media Tools, Research Competences, Health Sciences, COVID-19, Research Completion

Posted Date: March 18th, 2021

DOI: https://doi.org/10.21203/rs.3.rs-276109/v1

License: @ (i) This work is licensed under a Creative Commons Attribution 4.0 International License.

Read Full License 
1 Effect of Social Media Usage on Research Competences and Completion

2 during COVID-19: Case of Pre-Service Health Sciences Researchers

4

5 Muhammad Zaheer Asghar* MPhil, PhD zaheer.asghar@helsinki.fi

6 University of Helsinki, Department of Education, Helsinki, Finland

7 Seema Arif MPhil, PhD seema.arif@umt.edu.pk

8 University of Management and Technology, Department of Education, Lahore, Pakistan

9 Pirita Seitamaa-Hakkarainen PhD pirita.seitamaa-hakkarainen@helsinki.fi

10 University of Helsinki, Department of Education, Helsinki, Finland

11

12 Junaid Sarfraz Khan MBBS, FRCS, PhD, PhD

13 National University of Medical Sciences, Rawalpindi, Pakistan

14

15

16

17

18

19

20

21

22

23

24

25

26

27

28

29

30

31

*Correspondence: Muhammad Zaheer Asghar zaheer.asghar@helsinki.fi

32

University of Helsinki, Department of Education, Helsinki, Finland 
Effect of Social Media Usage on Research Competences and Completion

during COVID-19: Case of Pre-Service Health Sciences Researchers

37

\begin{abstract}
Introduction: Pandemic has proved to be a game-changer for higher education. The emerging context of using different social media tools for timely completion of their graduate and postgraduate research is evident among health sciences pre-service researchers during the pandemic.
\end{abstract}

Methods: A cross-sectional survey was conducted with health sciences preservice researchers $(n=410)$ enrolled in postgraduate health sciences programs of the Pakistani universities. The Vitae (2011) framework was considered to measure research competences of the pre-service researchers with the factors of personal effectiveness (PE), research knowledge and intellectual abilities (KI), research and governance (RG), and researcher's engagement and influence (EI) to disseminate research. Conclusions explicitly focused on using Social Media are drawn from the Structure Equation Model obtained via Smart PLS.

Results: The findings have highlighted that preservice health sciences researchers used different forms of social media to support their research completion during COVID-19. Multimedia tools helped pre-service researchers to share information through audio, video, and image sharing service on various networks. Information management tools such as google docs and monkey surveys were useful for data collection during COVID-19.

Conclusion: This study implicated that different forms of social media tools helped health sciences pre-service researchers develop their research competences, such as personal effectiveness, research governance, and research engagement, which ultimately influenced them to complete their research tasks on time in pandemics.

Keywords: Social Media Tools; Research Competences; Health Sciences; COVID-19; Research Completion. 


\section{Introduction}

72 The social chaos of COVID-19 had effect on education as well. It had a drastic effect on the world economy, higher education across the world has also turned topsy-turvy. Higher education is the source of the knowledge economy; therefore, its continuation was a big challenge. Hence, medical and health workers and students were also at the forefront against COVID-19; their education, especially timely completion of research, has been drastically affected. The education and research in health sciences were of utmost importance for two reasons; prepare health researchers against the pandemic and for research pandemic prevention and cure. The Higher Education Commission (HEC), Pakistan advised all universities and higher education Institutions to switch to online mode so that the continuation of education was not compromised.

The term "Social Media"(SM) refers to "the online technologies and practices that people use to share opinions, insights, experiences, and perspectives" (1). ResearchGate, Mendeley, Google Scholar, LinkedIn, Academia, Facebook, Twitter, and Google+ were the most frequently used SM sites by graduate students for academic purposes (2). According to a recent estimate, social media is increasingly becoming popular globally; more than 2.65 billion people were SM users, whereas this figure is expected to cross 3 billion by 2021(3). Such rapid growth in SM users indicates that SM has vast potential for knowledge sharing and networking (4). SM's use in health sciences is also extensive; customers of the health sector may use it to get better information about health services, get reviews on some therapeutic methods, or share their personal experiences about a health service (5). Social media is connecting health sciences research with practice. It is also helping the researchers connect for knowledge creation and dissemination. Though health sciences postgraduate students and faculty have been social media (SM) users, they sought mostly social media for communication with their supervisors, locating their target samples for data collection, and the use of social media in health sciences education $(6,7)$, research, and practice has become a trending research area during pandemic $(8,9)$.

The current research aims to investigates how SM tools helped (pre-service researchers enrolled in postgraduate programs of health sciences) complement their research skills to complete their degrees. 


\section{Literature Review}

Previous research reported that graduates' use of SM to develop research skills and timely completion of research is limited $(10,11)$. Web 2.0 technologies have more significant potential to connect the student researchers with their supervisors (12); SM creates virtual spaces where they can have one-toone meetings and direct feedback of the work instead of a passive review of the content, promoting trust and collaboration between the students and supervisors. This combination of technology and pedagogy provides innumerable ways to innovate and create virtual spaces where adequate research supervision can occur $(11,13)$.

Some scholars do not positively view SM's use; they claim that students get distracted and lose their focus, leaving a negative impact on researchers' productivity (14). Many scholars argue that SM's use deteriorates students' mental and psychological well-being causing an addiction (1, 15-17). According to previous research, the use of SM for pre-service researchers is more than spending leisure time and making friendships; it may involve sharing opinions (18), online learning (19), information exchange (20), personal promotion, submitting assignments (21), and dissemination of research outputs (2). Graduate students use social media tools to update literature, data collection and storage. SM tools also help students in collaboration, communication, and sharing of ideas. However, misinformation, quality of information, restrictions are barriers to adopt SM tools for research purposes.

The current research has endeavored to clarify social media tools' role to enhance research competences and the research completion process of the health sciences' postgraduate pre-service researchers during the pandemic.

The study posed the following research questions:

$\boldsymbol{R Q 1 . ~ H o w ~ m u c h ~ d i d ~ h e a l t h ~ s c i e n c e s ' ~ p o s t g r a d u a t e ~ s t u d e n t s ~ u s e ~ d i f f e r e n t ~ s o c i a l ~ m e d i a ~ t o o l s ~ f o r ~}$ research purposes during the pandemic?

RQ2. What is the role of different social media tools to enhance research competences for the postgraduate health sciences pre-service researchers' research completion process during a pandemic? 


\section{Conceptual Framework}

126 The current study has adopted Duman (22) classification of social media tools; social media usage in 127 general (SM) such as Facebook, Tweeter and WhatsApp; communication (COMM) tools such as Zoom,

128 Google hangout, Webinar and Skype; collaborative (COL) tools such as Wikipedia and Statpedia; 129 multimedia (MM) tools such as image, video, and audio; information management (IM) tools such as 130 Monkey survey and google doc. The Vitae (2011) research framework was considered to measure 131 research competences of the graduate students with the factors of personal effectiveness (PE), research 132 knowledge and intellectual abilities (KI), research and governance (RG), and researcher's engagement 133 and influence (EI) to disseminate research (23).

134 A visual depiction of these domains is shown in Figure 1.

\section{Social Media}

- SM= Social Media General (FB, WhatsApp etc.)

- $\mathrm{COMM=Communication} \mathrm{(Zoom,} \mathrm{Skype} \mathrm{etc.)}$

- $\mathrm{COL}=$ Collaborative (Wikipedia, Statpedia etc.)

- MM= Multi Media (Image, Video, Audio etc.)

- IM= Information Management (Monkey Survey, google docs. Etc.)

\section{Methodology}

145 It was survey research conducted in a positivist paradigm. An institutional ethics committee approved

146 the research plan. A G-power sample calculator was used to compute the sample size required for a

147 study that uses a structural equation model (SEM). It was calculated that the minimum sample size 400

148 was required, given the structural complexity of the model. A random sampling technique was used to select public $(n=4)$ and private $(n=4)$ universities with departments offering health sciences programs.
El=Engagement Influence
RC=Research Competences

- KI= Knowledge and intellectual

Figure 1. Conceptual framework

The study has the following hypotheses:

H1. There is an impact of social media tools on research competences development of the preservice health sciences researchers.

H2. There is a meditating role of research competences between social media tools and research completion. 
$151(n=410)$. The survey was filled by equal gender distribution of male $(n=204)$ and female $(n=206)$ health

152 sciences students.

153 An instrument of social media usage for research by Duman (22) was adopted to conduct the

154 survey. The instrument usage permission was taken from the author. A 5-point Likert type scale was

155 used to measure the factors ranging from $1=$ strongly disagree to $5=$ strongly agree.

156 The data were entered into SPSS software. Data screening was performed for outliers and

157 missing values. Robustness of the data was performed for the heterogeneity, endogeneity, and non-

158 linearity. PLS-Smart software was used to assess the confirmatory factor analysis, reliability, and

159 validity of the questionnaire (see appendix A) to proceed for mediation analysis at a bootstrapping level 1605000.

161

\section{Results}

163 The descriptive statistics showed that all factors were towards an agreement with normal skewness and

164 kurtosis values $(-1.96>\mathrm{x}<1.96$; see Table 1$)$.

165 Table 1. Descriptive statistics

\begin{tabular}{|c|c|c|c|c|c|c|}
\hline & Mean & $\begin{array}{l}\text { Std. } \\
\text { Deviation }\end{array}$ & Skewness & & Kurtosis & \\
\hline & Statistic & Statistic & Statistic & Std. Error & Statistic & Std. Error \\
\hline $\mathrm{COL}$ & 3.51 & 1.23 & -0.76 & 0.12 & -0.66 & 0.23 \\
\hline MM & 3.62 & 1.24 & -0.99 & 0.12 & -0.45 & 0.23 \\
\hline IM & 3.73 & 1.17 & -1.10 & 0.12 & 0.15 & 0.23 \\
\hline SM & 4.23 & 0.63 & -1.38 & 0.12 & 1.84 & 0.23 \\
\hline PE & 4.11 & 0.62 & -0.31 & 0.12 & -0.42 & 0.23 \\
\hline KI & 4.21 & 0.66 & -0.69 & 0.12 & 0.01 & 0.23 \\
\hline $\mathrm{RG}$ & 4.10 & 0.61 & -0.21 & 0.12 & -0.46 & 0.23 \\
\hline EI & 4.25 & 0.63 & -0.51 & 0.12 & -0.12 & 0.23 \\
\hline $\mathrm{CL}$ & 3.24 & 1.25 & -0.92 & 0.12 & -0.46 & 0.23 \\
\hline $\mathrm{COM}$ & 3.74 & 1.02 & -0.96 & 0.12 & -0.04 & 0.23 \\
\hline
\end{tabular}

167 Structural equation model was assessed for the exogenous construct's effect size on endogenous

168 variables, adjusted R-square and q-square (predict) of endogenous variables, and Stone-

169 Geisser'spredictive relevance (Q-square) of the endogenous variables according to Cohen (24) 
170 guidelines of a small, medium, and large effect size with the values $0.02,0.15$ and 0.35 respectively as

171 given in Table 2. The factor IM and COL were dropped from the model because of low values (see

172 Table 2).

173 Table 2. SEM model evaluation

\begin{tabular}{lcccccc}
\hline \multicolumn{2}{c}{ Variables } & \multicolumn{2}{c}{ Exogenous effect } & \multicolumn{3}{c}{ Endogenous Predictivity } \\
\hline Factors & Sub factors & $\begin{array}{c}\text { CL } \\
\text { f-square }\end{array}$ & $\begin{array}{c}\text { RC } \\
\text { f-square }\end{array}$ & $\begin{array}{c}\mathrm{Q}^{2} \\
\text { predict }\end{array}$ & $\begin{array}{c}\mathrm{Q}^{2} \\
(=1-S S E / S S O)\end{array}$ & $\begin{array}{c}\text { Adjusted R- } \\
\text { Square }\end{array}$ \\
\hline COL & - & - & 0.012 & - & - & - \\
COM & - & - & 0.023 & - & - & - \\
IM & - & - & 0.018 & - & - & - \\
MM & - & - & 0.049 & - & - & - \\
SMG & & - & 0.036 & - & - & - \\
CL & - & - & - & 0.463 & 0.416 & 0.423 \\
RC & - & 0.738 & - & - & 0.368 & 0.550 \\
& EI & - & - & 0.41 & - & - \\
& IM & - & - & 0.388 & - & - \\
& KI & - & - & 0.407 & - & - \\
& RG & - & - & 0.306 & - & - \\
\hline
\end{tabular}

$17 \overline{4}$

175 According to $\mathrm{Hu}$ and Bentler (25) suggestion, the model fit indices (NFI $<.07$ and $\mathrm{SRMR}>0.9)$

176 were found satisfactory (see Table 3).

177

Table 3. Model fit criteria

\begin{tabular}{lll}
\hline & Saturated Model & Estimated Model \\
\hline SRMR & 0.039 & 0.049 \\
d_ULS & 0.068 & 0.109 \\
d_G & 0.06 & 0.092 \\
Chi-Square & 126.385 & 193.347 \\
NFI & 0.953 & 0.929 \\
\hline
\end{tabular}

178

179 The SEM relations were studied for path coefficient and specific in-direct effects (see Figure 2). 


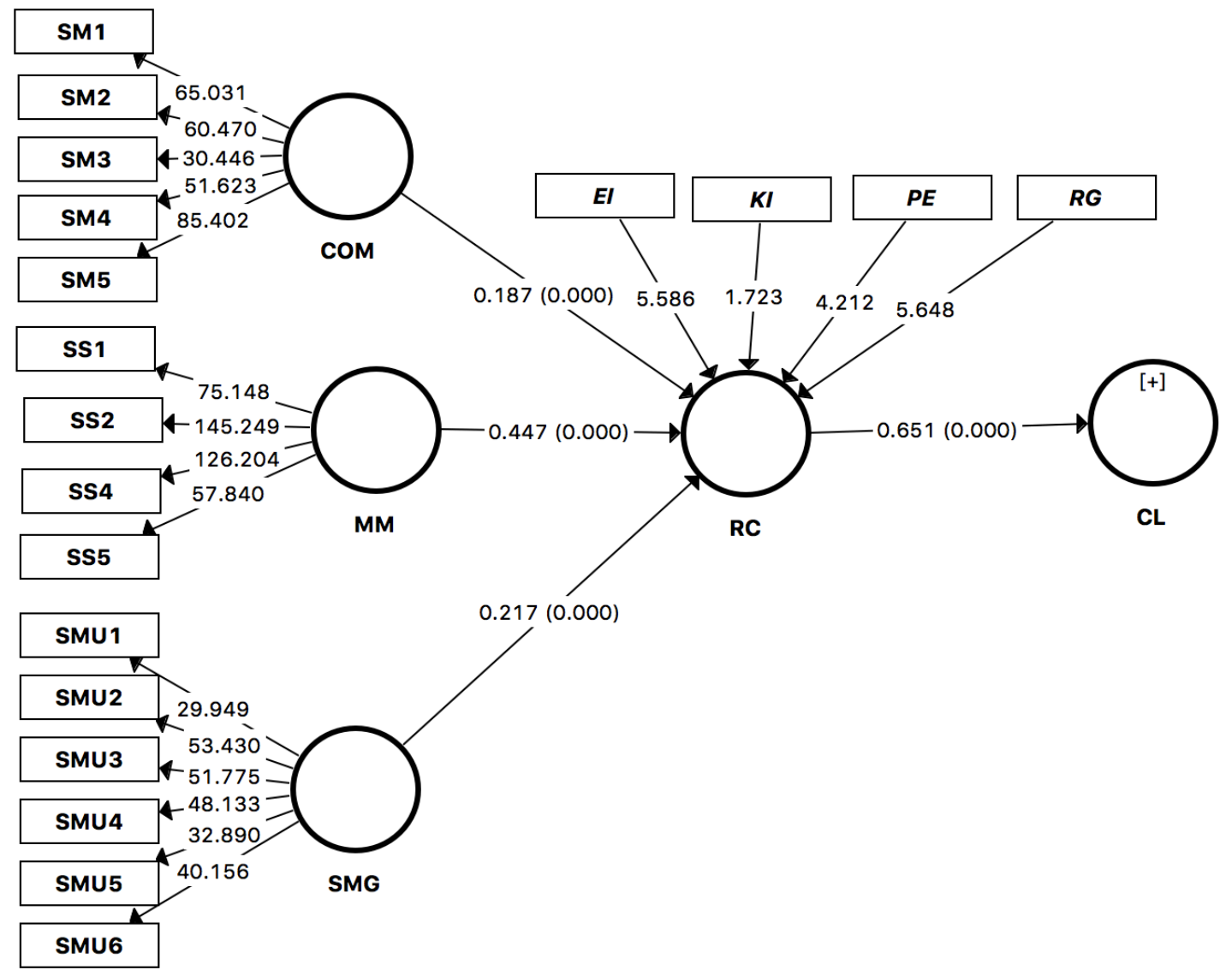

182

Figure 2. Effect of social media on research competences and completion

184 The path-coefficient, and relevant t-values at a bootstrap level 5000 were measured. Table 4

185 shows all significant paths with highest values for path: $\mathrm{RC} \rightarrow \mathrm{CL}(\beta=0.653, \mathrm{SE}=0.031, t(20.83)$ and $186 p<.001)$ and weakest path: $\mathrm{COM} \rightarrow \mathrm{RC}(\beta=0.189, \mathrm{SE}=0.047, t(3.93)$ and $p<.001)$. The weakest indirect 187 effect: $\mathrm{COM} \rightarrow \mathrm{RC} \rightarrow \mathrm{CL}(\beta=0.123, \mathrm{SE}=0.031, t(3.975), p<0.001)$ and strongest indirect effect is: $188 \mathrm{MM} \rightarrow \mathrm{RC} \rightarrow \mathrm{CL}(\beta=0.291, \mathrm{SE}=0.037, t(7.784), p<0.001)$.

189 Table 4. Direct and specific indirect effect

\begin{tabular}{lllllll}
\hline Hypothesis & & $\beta$ & SE & $t$-value & $p$ & Results \\
\hline H1 & $\mathrm{COM} \rightarrow \mathrm{RC}$ & 0.189 & 0.047 & 3.933 & 0.000 & Not rejected \\
$\mathrm{H} 2$ & $\mathrm{MM} \rightarrow \mathrm{RC}$ & 0.446 & 0.048 & 9.352 & 0.000 & Not rejected \\
$\mathrm{H} 3$ & $\mathrm{RC} \rightarrow \mathrm{CL}$ & 0.653 & 0.031 & 20.832 & 0.000 & Not rejected \\
H4 & $\mathrm{SMG} \rightarrow \mathrm{RC}$ & 0.218 & 0.043 & 5.001 & 0.000 & Not rejected \\
$\mathrm{H} 5$ & $\mathrm{COM} \rightarrow \mathrm{RC} \rightarrow \mathrm{CL}$ & 0.123 & 0.031 & 3.975 & 0.000 & Not rejected \\
$\mathrm{H} 6$ & $\mathrm{MM} \rightarrow \mathrm{RC} \rightarrow \mathrm{CL}$ & 0.292 & 0.037 & 7.784 & 0.000 & Not rejected \\
\hline
\end{tabular}

190 
192 Discussion

193 The study was aimed to measure different social media tool usage by health sciences pre-service

194 researchers during the pandemic. The study aimed to find social media's role in the students' research

195 competences development for their research completion process. The research questions under

196 discussion are:

197 RQ1. How much did health sciences' postgraduate pre-service researchers use different social

198 media tools for research purposes during the pandemic?

199 The results confirmed that with the increasing awareness of social media tools and technologies'

200 positive outcomes, their usage among graduate and postgraduate pre-service researchers is steadily

201 rising. Pre-service researchers are also very enthusiastic about discovering new techniques and methods

202 to enhance their research quality.

203 The student used social media such as Facebook, WhatsApp, and Instagram, to link with their 204 class fellows. Many governments have partnered with WhatsApp to provide updated information about

205 COVID-19 (4, 26-28). Pakistan health ministry and many other health agencies also provide 'real-time'

206 data about public health, and COVID-19 spread on Facebook and Twitter, which was of great concern

207 for health sciences researchers.

208 SM tools, Skype, and Zoom were extensively used by pre-service researchers enrolled in 209 postgraduate programs of health sciences which used for necessary communication with the supervisor 210 and conducting interviews. Knowledge sharing is one of the effective strategies for graduate research.

211 SM has infiltrated the academic life profusely; therefore, it is the time to harness this energy (29).

212 Faculty and students must exploit the SM resources to excellence in higher education systems by

213 creating informal chat groups intra-student, student-faculty, and interfaculty, for meeting research and 214 study goals.

215 Collaborative tools such as Wikipedia and Statpedia were also helpful for content development

216 and data analysis. Information management tools like google docs and monkey surveys proved useful

217 for data collection during COVID-19, while multimedia tools helped pre-service researchers to share

218 information through audio, video, and image sharing service for research dissemination. A study on 
219 Wikipedia and Reddit showed that the correlation of collaborative social media site visits on COVID-

22019 information was reduced with the increasing news of COVID-19 on other social media sources (30).

221 The same rule is also applicable for health sciences novice researchers who have data on other social

222 media networks.

223 This study has also concluded that different forms of social media tools also helped health sciences pre-service researchers develop their research competences, such as personal effectiveness, research governance, and research engagement, which ultimately resulted in timely completion of their research tasks during pandemic.

Pre-service researchers used information management tools, such as Monkey surveys and

228 Google Docs, for data collection during the pandemic. Previous studies $(3,31,32)$ showed that graduate students had frequently used information management tools, file sharing, research databases, and reference management tools to complete their research. The successful use of SM tools boosted the self-efficacy and transformed their negative attitudes into positive ones $(20,33)$. Similarly, other studies examining the students' perceptions and beliefs about social media indicated that social media tools' utilization increased with a positive attitude towards social media $(3,31,32)$. In their

234 thesis/dissertation's active writing process, graduate students used tools like reference management, academic databases, online library catalog, and file services.

RQ2. What is the role of different social media tools to enhance research competences for the postgraduate health sciences pre-service researchers' research completion process during a pandemic? Multimedia tools such as video, audio, and images greatly influence research competency

239 development, leading to research completion. Multimedia tools are part of all social media sites and are

240 frequently used by health sciences preservice researchers. Research has shown effects of audio, video,

241 and image through digital and social media tools to develop language students' research competences

242 (34). Social media networks such as Facebook and Twitter also have a more substantial effect than other social media tools on research competences and research completion process. A study in Malaysia has shown that using social media enhances pre-service researchers' collaboration with faculty and peers, their research engagement, and research skills (35). 
The study has shown that collaborative social media tools were not essential to enhance

247 research competences for their research completion. Therefore, it was dropped from the model due to

248 its weak effects on research competences. Abilock (36) says that although collaborative social media

249 sites like Wikipedia are unreliable, our pre-service researchers still use them as a source of learning.

250 Information management tools have shown a weak effect on research competences in the primary evaluation of the model. Information management tools were removed from the model because their effect size on competences development was weak. Nevertheless, the information management tools facilitated researchers in pandemic for data collection but not for research competences development. Blount (37) confirms that information management tools such as google doc helped gather and manage telework during COVID-19.

Social media communication tools such as zoom, google hangout, and webinars were useful for developing research competences and research completion. Another research (38) depicted the same result during the pandemic that showed the impact of social media on scholarly communication in response to COVID-19. Our results align with previous research that information sharing and

260 knowledge sharing increased during COVID-19 (39), and graduate students used the SM sites to 261 improve their research competences (40). Increased use of social media sites enhanced students' 262 capability to use Web2.0 technologies for research purposes. Knowledge sharing is one of the significant strategies of graduate research. Lovitts (2008) had proclaimed that graduate students' immediate context affected their choice of SM tools for research.

265 The microenvironment, including interactions between the students and supervisor, influences tools and 266 willingness to complete research. This study has shown that social media influences research 267 competences, such as research engagement, research governance, and personal influence. Social media 268 influences pre-service researchers' research engagement due to its feature of networking, disseminating 269 information, and developing public awareness about recent research developments (41). Social media has also proven as an essential tool for decision-making through bibliometrics measurement that helps in research governance (42). 


\section{Conclusion}

274 Preservice health sciences researchers used different forms of social media to support their research

275 completion process during COVID-19. The student used social media in general, such as Facebook,

276 WhatsApp, and Instagram, to interact with their class fellows, researchers, peers, and mentors. They

277 extensively used social media for research communication, such as Skype and Zoom. Collaborative

278 tools such as Wikipedia and Statpedia were also helpful for them. Multimedia tools helped pre-service

279 researchers to share information through audio, video, and image sharing service on all sorts of social

280 media networks. Information management tools such as google docs and survey monkey-were useful

281 sources for data collection during COVID-19.

282 Different forms of social media tools also helped health sciences pre-service researchers

283 develop their research competences, such as personal effectiveness, research governance, and research

284 engagement, which ultimately influenced them to complete their research tasks on time in pandemics.

\section{Implications}

286 Graduate education is not free and costs highly to its customers; developing countries and their universities have limited resources to expand their research resources. The research is a much-wanted product for a university's reputation and seeks higher worldwide rankings $(43,44)$. Timely completion of the degree is obligatory in Pakistan; otherwise, its cost may rise inexplicably. Mostly, in the COVID19 scenario, the pre-service researchers who could connect with their supervisors were able to continue

291 their research. It was not a one-time situation; living in turbulent times, the universities must gear up their staff and students to meet such challenges in the future. Higher education itself is slowly moving towards emergent technologies for online and blended learning through social media networks.

\section{Declarations}

\section{Ethics approval and consent to participate}

296 The data collection in the present study was conducted after the approval of Universitat Oberta de

297 Catalunya, Barcelona, Spain ethics committee dated 20 May 2020. We confirm that all methods used

298 in this study were carried out in accordance with relevant guidelines and regulations. The 
299 participation of students was completely voluntary and informed consent was obtained from all

300 participants or, if participants are under 18, from a parent and/or legal guardian.

\section{Consent for publication}

302 Not applicable.

\section{Availability of data and materials}

304 The datasets used and/or analyzed during the current study are available from the corresponding author 305 on reasonable request.

\section{Authors' contributions}

307 Asghar \& Hakkarainen framed, organized and reviewed the study

308 Arif \& Khan wrote the literature and discussion

309 Asghar \& Arif performed data analysis, table formation and interpretation.

310 Hakkarainen \& Khan revised the paper.

311 Asghar \& Arif arranged references.

312 All authors reviewed the manuscript.

\section{Competing Interest}

314 The authors declare that they have no competing interests.

\section{Funding}

316 The author(s) received no financial support for the research.

\section{Acknowledgements}

318 Not applicable.

\section{References}

321 1. Cann A, Dimitriou K, Hooley T. Social media: A guide for researchers. 2011.

322 2. Van Noorden R. Online collaboration: Scientists and the social network. Nature News.

$3232014 ; 512(7513): 126$. 
324 3. Saadeh RA, Saadeh NA, Magda A. Determining the usage of social media for medical

325 information by the medical and dental students in northern Jordan. J Taibah Univ Med Sci.

$3262020 ; 15(2): 110-5$

327 4. De Gagne JC, Koppel PD, Kim SS, Park HK, Rushton S. Pedagogical foundations of

328 cybercivility in health professions education: a scoping review. BMC Med Educ. 2021;21(1):79.

329 5. Guraya SY. The usage of social networking sites by medical students for educational

330 purposes: a meta-analysis and systematic review. N Americ J Med Sci. 2016;8(7):268.

331 6. AlFaris E, Irfan F, Ponnamperuma G, Jamal A, Van der Vleuten C, Al Maflehi N, et al. The

332 pattern of social media use and its association with academic performance among medical students.

333 Med Teach. 2018;40(sup1):S77-S82.

334 7. Bahner DP, Adkins E, Patel N, Donley C, Nagel R, Kman NE. How we use social media to

335 supplement a novel curriculum in medical education. Med Teach. 2012;34(6):439-44.

336 8. Ramani S, McKimm J, Findyartini A, Nadarajah VD, Hays R, Chisolm MS, et al. Twelve tips

337 for developing a global community of scholars in health professions education. Med Teach. 2020:1-6.

338 9. Mehta N, End C, Kwan JCS, Bernstein S, Law M. Adapting medical education during crisis:

339 Student-Faculty partnerships as an enabler of success. Med Teach. 2020:1-2.

340 10. Green P, Bowden J, Green P. Completion mindsets and contexts in doctoral supervision. Qual

341 Assur Educ. 2012;20 (1):67-80

342 11. Maor D, Ensor JD, Fraser BJ. Doctoral supervision in virtual spaces: A review of research of

343 web-based tools to develop collaborative supervision. High Educ Res Dev. 2016;35(1):172-88.

344 12. Lahiry S, Choudhury S, Chatterjee S, Hazra A. Impact of social media on academic

345 performance and interpersonal relation: A cross-sectional study among students at a tertiary medical

346 center in East India. J Educ Health Promot. 2019; 8: 73.

347 13. Dron J. The pedagogical-technological divide and the elephant in the room. Int J E-learn.

$348 \quad 2012 ; 11(1): 23-38$.

349 14. Mohorjy A, Al-Sharqi L, Hashim K, Kutbi I. Gender differences on perceptions of social

350 media as a learning tool. West East J Soc Sci. 2015;4(1/2):10. 
351 15. Webb MC, Wasilick LM. Addressing social media addiction via the classroom. J Heal Educ

352 Teach Techniques. 2015;2(3).

353 16. Dwyer R, Fraser S. Addicting via hashtags: How is Twitter making addiction? Contemp Drug 354 Prob. 2016;43(1):79-97.

355 17. Kuss DJ, Griffiths MD. Social networking sites and addiction: Ten lessons learned. Inter J 356 Enviro Res Pub Health. 2017;14(3):311.

357 18. Wiid JA, Cant MC, Nell CE. Perceptions and uses of social media networking systems by

358 South African students. IBER. 2014;13(4):715-26.

359 19. Salmon G, Ross B, Pechenkina E, Chase A-M. The space for social media in structured 360 online learning. Res Learn Tech. 2015;23.

361 20. Al-Sharqi LM, Hashim K, Ahmed HA. Perceptions of social media as a learning tool: a 362 comparison between arts and science students. Int J Soc Media Interac Learn Enviro. 2016;4(1):92363108.

364 21. Subramani R. The academic usage of social networking sites by the university students of 365 Tamil Nadu. Online J Commun Media Tech. 2015;5(3):162.

366 22. Duman M. Graduate students' use of social media tools for thesis/dissertation research:

367 Middle East Technical University; 2015.

368 23. Vitae. Researcher development framework. Careers Research and Advisory Centre 369 Cambridge; 2011.

370 24. Cohen S. Perceived stress in a probability sample of the United States. 1988. COHEN S.

371 Perceived stress in a probability sample of the United States. Soc Psych Health. 1988:31-67.

372

373 25. Hu Lt, Bentler PM. Cutoff criteria for fit indexes in covariance structure analysis:

374 Conventional criteria versus new alternatives. Struct Equ Model a Multidiscip J. 1999;6(1):1-55.

375 26. Chen T, Peng L, Yin X, Rong J, Yang J, Cong G, editors. Analysis of user satisfaction with 376 online education platforms in China during the COVID-19 pandemic. Healthcare; 2020:

377 Multidisciplinary Digital Publishing Institute. 
378 27. Salam MAu, Oyekwe GC, Ghani SA, Choudhury RI. How can WhatsApp ${ }^{\circledR}$ facilitate the

379 future of medical education and clinical practice? BMC Med Educ. 2021;21(1):54.

380 28. Oyekwe GC, Ghani SA, Choudhury RI. How can WhatsApp ${ }^{\circledR}$ facilitate the future of medical 381 education and clinical practice? BMC Med Educ. 2021;21(1).

382 29. Omotayo FO, Salami OM. Use of Social Media for Knowledge Sharing Among Students. 383 Asian J of Info Sci Tech. 2018;8(2):65-75.

384 30. Gozzi N, Tizzani M, Starnini M, Ciulla F, Paolotti D, Panisson A, et al. Collective Response 385 to Media Coverage of the COVID-19 Pandemic on Reddit and Wikipedia: Mixed-Methods Analysis.

386 J Med Internet Res. 2020;22(10):e21597.

387 31. Browning L, Gerlich RN, Westermann L. The New HD Classroom: A" Hyper Diverse" 388 Approach to Engaging with Students. J Instr Pedago. 2011;5(1).

389 32. Poellhuber B, Anderson T, Roy N. Distance students' readiness for social media and 390 collaboration. Int Rev Res Open Distri Learn. 2011;12(6):102-25.

391 33. Joyce KM, Brown A. Enhancing social presence in online learning: Mediation strategies 392 applied to social networking tools. Online J of Dist Learn Admin. 2009;12(4).

393 34. Golovchun A, Zhumabekova G, Turlybekova A, Muktarova E, Zhusupbekov A. The

394 Development of Research Competence Through Digital Resources. J Talent Dev Excell.

$3952020 ; 12(1): 633-41$.

396 35. Al-rahmi WM, Othman MS, Yusuf LM. Using social media for research: The role of

397 interactivity, collaborative learning, and engagement on the performance of students in Malaysian

398 post-secondary institutes. Mediterr J Soc Sci. 2015;6(5):536.

399 36. Abilock D. True--or Not? Educ Leadersh. 2012;69(6):70-4.

400 37. Blount Y. Working anywhere management opportunities and challenges. Anywhere working 401 and the future of work: IGI Global; 2020. p. 1-22.

402 38. Sobaih AEE, Hasanein AM, Abu Elnasr AE. Responses to COVID-19 in higher education:

403 Social media usage for sustaining formal academic communication in developing countries.

404 Sustainability. 2020;12(16):6520. 
405 39. Nugroho A, Coulter RW, Erasmus V, Laksmono PA, Mihari TS, Richardus JH. Evaluation of

406 a training aimed at building capacity for outreaching to men who have sex with men and transgender

407 women in Indonesia. Health Educ Res. 2019;34(2):223-33.

408 40. Carpenter J. Researchers of Tomorrow: The research behaviour of Generation Y doctoral

409 students. Info Serv Use. 2012;32(1-2):3-17.

410 41. Helm CW. Social media is essential for research engagement: AGAINST: Likes trumped by

411 dislikes. BJOG An Int J Obstet Gynaecol. 2017;124(6):903-907.

412 42. Gilani E, Salimi D, Jouyandeh M, Tavasoli K, Wong W. A trend study on the impact of social

413 media in decision making. Int J Data Netw Sci. 2019;3(3):201-22.

414 43. Arif S, Ilyas M, Hameed A. Using structure equation modeling to construct student

415 satisfaction models for private universities of Pakistan. J Qual Tech Manage. 2017;14(II):39-73.

416 44. Khawar A, Arif S. Building World-Class University in Pakistan: Opportunities and

417 Constraints. J Manage Res. 2019;6(2):85-112.

418

419 
Figures

\section{Social Media}

- $\mathrm{SM}=$ Social Media General (FB, WhatsApp etc.)

- COMM=Communication (Zoom, Skype etc.)

- $\mathrm{COL}=$ Collaborative (Wikipedia, Statpedia etc.)

- $\mathrm{MM}=$ Multi Media (Image, Video, Audio etc.)

- IM= Information Management (Monkey Survey, google docs. Etc.)

\section{$\mathbf{R C}=$ Research Competences}

- KI= Knowledge and intellectual abilities

- $P E=$ Personal effectiveness

- RG=Research Governance

- El=Engagement Influence
$\mathrm{CL}=$

Research

Completion Level

\section{Figure 1}

Conceptual framework

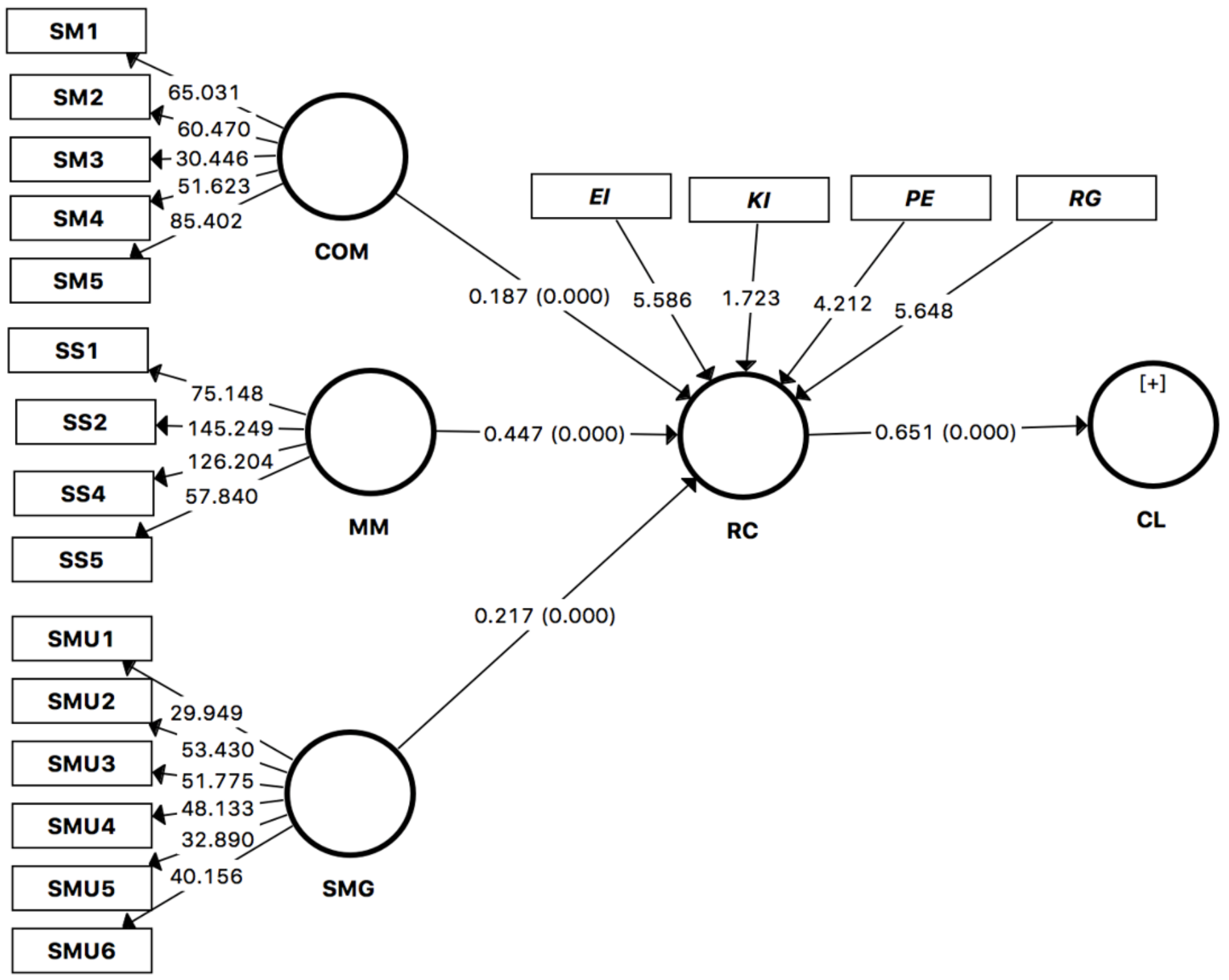

Figure 2 
Effect of social media on research competences and completion

\section{Supplementary Files}

This is a list of supplementary files associated with this preprint. Click to download.

- AppendixA23JAN.docx 